\title{
TOKENIZATION OF EDUCATIONAL ASSETS BASED ON BLOCKCHAIN TECHNOLOGIES
}

\author{
Olexander Shmatko, Tetyana Borova, Serhii Yevseiev, Oleksandr Milov
}

Possible scenarios for using blockchain technology in the field of education are considered. Methods and technologies of tokenization of assets, related to the educational process, are investigated. It is concluded, that the blockchain technology is decentralized and transparent with a high degree of reliability, which ensures the equality of all users of the chain's services. The transparency of the technology guarantees the participants in the process against abuse and forgery of documents. The study of the features of smart contracts made it possible to form the advantages of smart contracts in the field of education. This is, first of all, the conclusion of agreements without the participation of third parties, as well as the security and confidentiality of agreements. This ensures that the terms and subject of the agreement are kept secret, and that no one else can amend the agreement. At the same time, storing the contract in encrypted form ensures its confidentiality. A decrease in the cost of operations was noted. Tokenization of educational assets is considered on the example of preparing and defending a thesis with the subsequent registration of a diploma. The processes of passing the thesis in the context of using blockchain technology and issuing smart contracts are considered in detail. The advantages of using blockchain technology and smart contracts are illustrated with specific examples.

A study of the means and mechanisms for ensuring the confirmation of the authenticity of educational documents, the confidentiality of students' personal cards, and student identification has been carried out.

To create a decentralized distributed ledger for tokenization of educational assets, it is proposed to use blockchain technology and smart contracts based on the Ethereum platform

Keywords: tokenization, educational assets, blockchain, smart contracts, consensus algorithms, decentralized register

How to cite:

Shmatko, O., Borova, T., Yevseiev, S., Milov, O. (2021). Tokenization of educational assets based on blockchain technologies. ScienceRise: Pedagogical Education, 3 (42), 04-10. doi: http://doi.org/10.15587/2519-4984.2021.232321

This is an open access article under the Creative Commons CC BY license

\section{Introduction}

At present in the world there is a revolutionary transition from informatization of the main spheres of human activity to their digitalization.

If informatization involves, in essence, the modernization of certain human activities through the use of information and communication technologies, the digital transformation (or digitization) in its turn involves their qualitative transformation, departure from the usual types and forms of activity to the new ones, based on digital models and technologies [1].

The development of the digital environment requires the support and development of both existing conditions for the emergence of promising end-to-end digital platforms and technologies, as well as the creation of conditions for the emergence of new platforms and technologies.

The main end-to-end digital technologies are:

- big data;

- neurotechnology and artificial intelligence;

- distributed registry systems (blockchain);

- quantum technologies;

- new production technologies;

- industrial internet;
- components of robotics and sensors;

- wireless communication technologies;

- virtual and augmented reality technologies.

Continuing the cycle of work on the digital transformation of education [2-4], the paper conducts research on the use of blockchain technology (blockchain) for the tokenization of educational assets and promising areas of its implementation in education.

\section{Literary review}

According to Melanie Swan's book "Blockchain [5]: Scheme of the New Economy", there are three conditional areas of application of this technology: Blockchain 1.0 is currency. Cryptocurrencies are used in various applications, related to money, such as transfer systems and digital payments.

Blockchain 2.0 comprises contracts. Whole classes of economic, market and financial applications, which are based on the blockchain, conforn to different types of financial instruments - stocks, bonds, futures, mortgages, legal titles, smart assets and smart contracts.

Blockchain 3.0 - applications are those that go beyond financial transactions and markets [6]. This area will include the blockchain in education. 
The following blockchain options may prove fairly topical in education:

1) student's identity card;

2) confirmation of university accreditation;

3) intellectual property;

4) identification of students.

Consider them in more detail.

1. Using the blockchain as a student's personal card. In work [7] the personal card of the student, in which the success, training achievements as well as personal achievements of the given student will be stored, is offered. The advantage of the application is that each student will be able to have a resume, containing one's records and the evidence of all personal knowledge, skills and abilities, which will significantly reduce cases of fraud, associated with forgery of resumes. It also significantly reduces the workload of organizations and individuals who need to check this resume depending on the form of implementation.

2. Using a blockchain technology to verify accreditation. Currently, there are, literally, hundreds of ways of accreditation in Europe. With regard to public accreditation, each country has its own accreditation system of organizations and agencies that accredit them, as well as different systems for different organizations.

To find out if a diploma has been issued by a legal institution, an individual will need to check:

- if the institution did issue a specific diploma. No confirmation of the quality of education, provided by such a diploma, is presented.

- the accreditation body, whether it has truly accredited the institution;

- the authority whether the accreditation bodies are really authorized to act.

The above process is extremely time consuming and technically complex.

With the account, taken of the above areas, not only educational institutions use digital diplomas, but also the organizations that accredit them, placing their digital signatures in the blockchain. This will verify not only that student $\mathrm{X}$ has actually received a diploma from institution $\mathrm{Y}$, but also that the institution $\mathrm{Y}$ has been certified by the $\mathrm{Z}$ accreditation organization.

[8] puts forward a system that can be used to ensure that an educational organization, issuing diplomas, is officially licensed by the government or to ensure that an educational organization has special quality certificates.

3. Blockchain for intellectual property tracking. Currently, the tracking of intellectual property is an expensive business, carried out by certain specialized organizations, usually when the case is significant enough. Thus, collection agencies track the use of intellectual property of music and video to collect "royalties" [9], while magazine companies track article citations because this data is primarily valuable through its use for academic advancement. Due to the difficulty of tracking intellectual property, it is difficult for people who self-publish information to track and advertise the re-use of their intellectual property.

Using blockchain technology in the future, scientists will publish their works in open educational resources and record the links they used. This will notarize the date of publication and copyright, as well as track the level of reuse of any particular resource.

The advantage of this approach, from a structural point of view, is that this scenario is very similar to the existing system, used to track citations for journal articles. However, citation tracking still requires intermediaries to restrict the use of these articles, often in the form of high access costs and restrictions on sharing and use of intellectual property. This limits the use of an open educational resources model.

Using a blockchain eliminates the middleman, allowing anyone to openly publish and accurately track reuse without restrictions on the source material.

4. Using student identification. In large educational institutions one needs to regularly identify oneself with different departments of the organization. In view of this, each part of the organization collects student data for itself, or uses single-sign-on technology, whereby one shared copy of the student's data is used by all parties within the organization. In these two models, dozens if not hundreds of people can access the personal information of the learners. To ensure data security, it is necessary to manage access rights for all these people, as well as to ensure their security and protection against hacking [10].

This approach is fairly advantageous as its use in the identification process allows only those, responsible for verifying the student's identity, the access to the data. In addition, the only person who owns the data is the student him/herself. This means that the organizations no longer need to manage complex access rights systems, but only protect the device or network where the verification takes place. This will save some significant resources, spent on strengthening the network, combating data breaches, training staff on data protection and managing access rights. In addition, individuals who interact with the students in the organization should not take responsibility for the confidentiality of the data, as they will not need to know it.

\section{The aim and objectives of the study}

The aim of the research is to study the processes of tokenization of educational assets, applying blockchain technology and smart contracts.

To achieve this aim, the following objectives are accomplished:

- to define the essence and mechanisms of blockchain technology;

- to describe the essence and features of smart contracts;

- to determine the applicability of blockchain technology and smart contracts for the tokenization of assets in the education system.

\section{Materials and methods}

Blockchain enables the entire mankind to optimize most diverse spheres of life. One of the advantages of this technology is that it is almost unbreakable and there is no need to involve third parties. The fundamentals of the blockchain are based on mathematics and cryptography. Eventually, the blockchain will penetrate into all areas of activity, including education. At present, there are a number of problems in education. One of the 
important ones is fraud in the field of forgery as well as the issue of document retention.

\subsection{The essence and mechanisms of blockchain} technology

The basic blockchain system is an ever-growing sequence of blocks that are shared between participants through peer-to-peer networks. As a result, a database is formed, which is managed autonomously, without a single center. This makes the blockchain very convenient for logging events and data operations, managing identification and verifying the document origin.

A timestamp (hash sum) is added to each block. These blocks are strictly in a certain order, formed into chains ("blockchain" - literally "chain of blocks"). If one tries to rearrange the sequence of blocks, the system will reject the chain due to the mismatch of both the structure and the hash sum. Each block stores its hash code, summed up with the hash code of the previous block, which builds a one-way relationship between the blocks in the chain. Schematically, this can be represented in Fig. 1.

To avoid changing the timestamp and list the hash amount that will be correct from the point of view of the system, the blockchain uses several methods of protection: Proof of Work (PoW, proof of work) and Proof of Stake (PoS, proof of ownership).

Summarizing all the facts, it is not difficult to conclude that the blockchain is both highly reliable and decentralized at the same time. All the participants who support the chain service are equal. There is no server or any processing center.

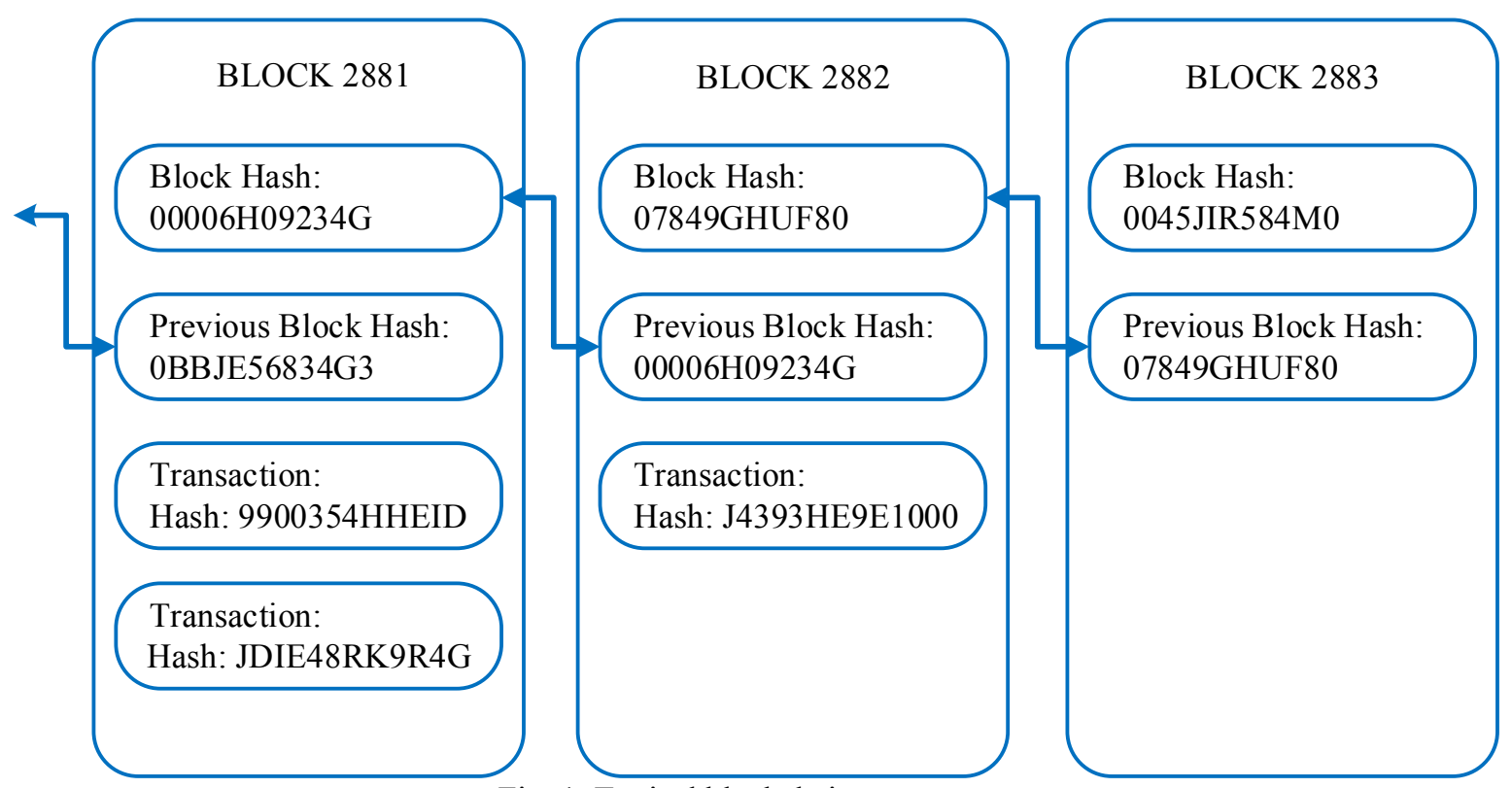

Fig. 1. Typical blockchain structure

The main element in all technology is forming and closing blocks. As mentioned above, each link in the chain (block) contains a specific key. Until it is decrypted, the block will not close. Mining is responsible for decryption into cryptocurrency. Miners, engaged in the extraction of cryptocurrency, do so with the help of some video cards and processors. Those, in turn, perform computational operations, the main purpose of which is to find a cryptographic signature to the block in the form of a hash. As soon as it is selected - the unit closes, and the miner receives a reward in the form of cryptocurrency.

The operation of the blockchain proper and its security is ensured by miners and other participants in the blockchain. They are also called nodes. Full nodes imply a miner and ordinary users of full-fledged wallets. This means that they have the full version of the blockchain on their computer or other device. The more active full nodes in the blockchain, the faster the transaction information is processed.

Summing up the interim results, the following are the key features of Blockchain [11]:

1. Decentralization - there is no server in the chain. Each participant is a server. It supports the entire blockchain;
2. Transparency - information about transactions, contracts and so on is stored in the public domain. However, these data cannot be changed;

3. Theoretical infinity - theoretically the blockchain can be supplemented with records to infinity. Therefore, it is often compared to a supercomputer;

4. Reliability - recording new data requires a consensus of blockchain nodes. This allows one to filter transactions and write only legitimate transactions, so it is impossible to replace the hash.

\section{technology \\ 4.2. The essence and mechanisms of blockchain \\ Smart contracts are essentially programs that} are created on the basis of computer logic and transmitted in the form of code [12]. That is why the parties to the agreement or contract can be sure that all the terms of the contract will be met, and none of the parties will be able to change the terms or interpret for their own sake.

The following main objects are distinguished in smart contracts: 
- signatories - the parties to the agreement who have accepted the agreed conditions (for this purpose an electronic signature or multi-signature is used);

- the subject of the contract - in fact, the resources for exchange. In this case, they must be within the system, within which the contract is implemented;

- the terms of the contract - more precisely, a mathematically confirmed description of the conditions, under which the contract will be considered fulfilled.

Obviously, the main advantage of smart contracts is the conduct of agreements without the involvement of third parties (in normal circumstances, they act as guarantors of the contract).

The second advantage of smart contracts is the security and confidentiality of transactions. All contracts are stored in the blockchain in the encrypted form. Only the parties to the contract know about the terms and object of the contract, and no one can introduce changes to the program code. The third advantage is the operation cost reduction. If the terms of the agreement are met, users exchange assets instantly. No additional confirmation is required. It is not to be that a smart contract is, first of all, a program. And, like any program, it is not without certain drawbacks:
1. The complexity of self-drafting smart contracts.

2. High dependence on the human factor (errors that were made when writing a program code).

3. Insufficient flexibility (data in the blockchain is not variable).

4. Poor scalability (when running multiple contracts at the same time, the system bandwidth is reduced).

A short work algorithm is as follows: the client on his/her computer generates a pair of long prime numbers a public and private key. A private key is considered secret because it can decrypt what is encrypted by the public one, and it also works in reverse.

If the public key is available to another blockchain user, he/she will be able to encrypt any message so that only a specific user can read it, as he/she owns a private one. Another feature of the public key - one can use it to verify that the data was encrypted with the private key of the client, without decrypting the data itself.

This ensures the openness as well as the security of the network. Ealier banks used to be responsible for this, while, at present, the blockchain mathematics become responsible. The entire process, described above, can be represented as the following scheme, shown in Fig. 2, examplifying some money transfer situation.

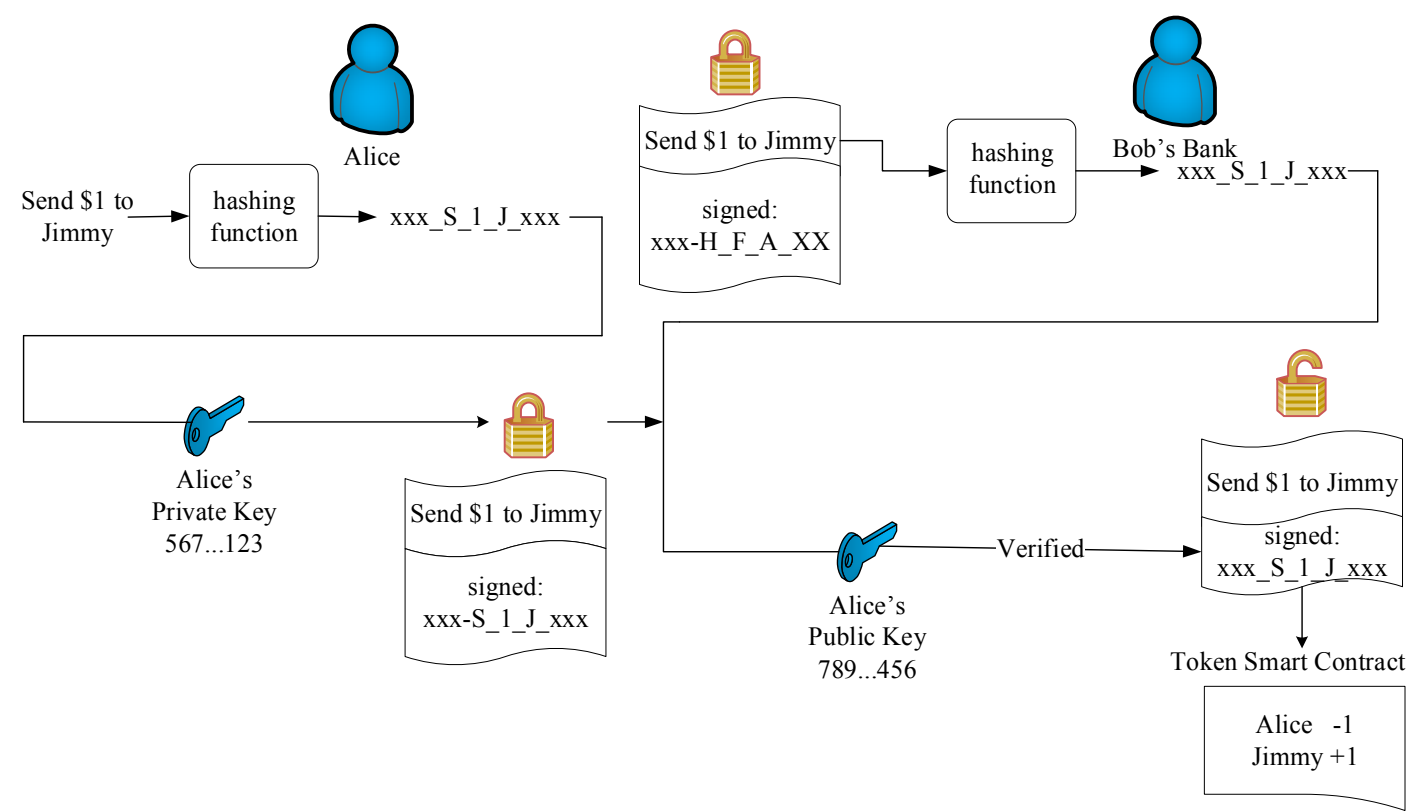

Fig. 2. Standard transaction in Ethereum [13]

\subsection{Application of blockchain technology and smart contracts for the tokenization of assets in the education system}

Now, educational institutions issue and store diplomas on paper, being strictly reporting forms. These diplomas are expensive to issue, service and test.

A public key infrastructure, such as printing and signing, requires the use of a certification authority as an intermediary to issue certificates, thus, creating a dependency that can be broken. In the event of natural disasters or wars, these documents may also be destroyed. Currently, the process of issuing and storing diplomas is very long and time consuming. Fig. 3 shows this process.

The defense of the diploma is held at a closed meeting of the Examination Commission (EC). At the end of the defense, the deferred marks are announced.

The diploma is signed by the rector of the educational institution. All documents have to be certified by a clear seal of the educational institution. 


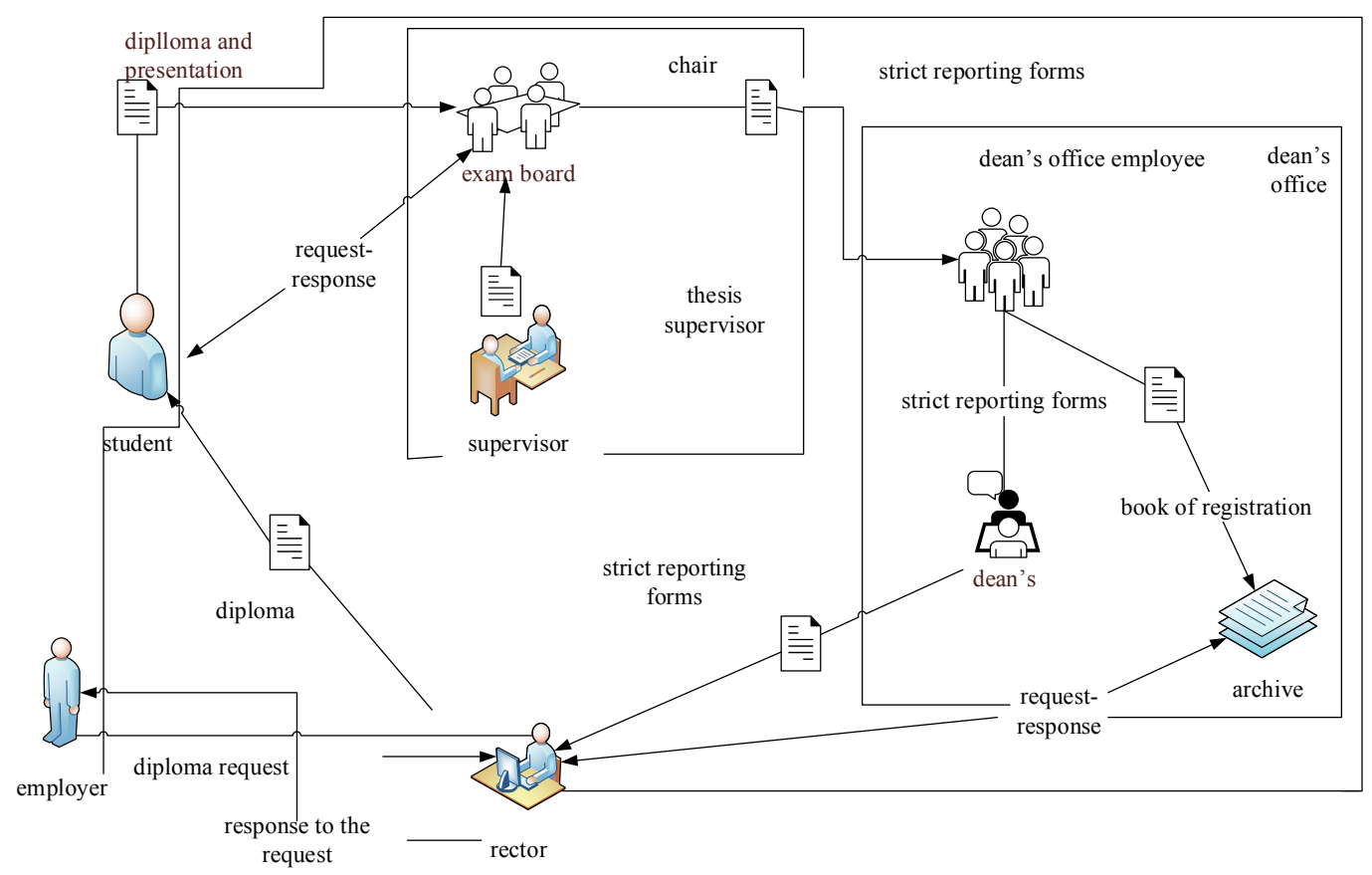

Fig. 3. The procedure for issuing and storing diplomas checked.

Once the form is completed, it must be carefully

A document that contains errors is considered corrupted, to be further destroyed in a specially designated manner.

The diploma is issued to the student in person or on the application is sent by the registered mail. The application is kept in the personal file of the graduate, and also there is a copy of the issued diploma.

All documents are forms of strict reporting and are taken into account in a special register.
To record all diplomas issued, the educational institution keeps a registration book, the letters of which are numbered, and the book itself is bound and the seal of the educational institution is put on it, indicating the number of sheets. The book is also stored as a document of strict reporting. To solve the problems of fraud in the field of documents forgery, as well as the problem of document storage, the paper proposes to introduce tokenization of educational assets using blockchain technology.

The model of tokenization of educational assets is presented in Fig. 4.

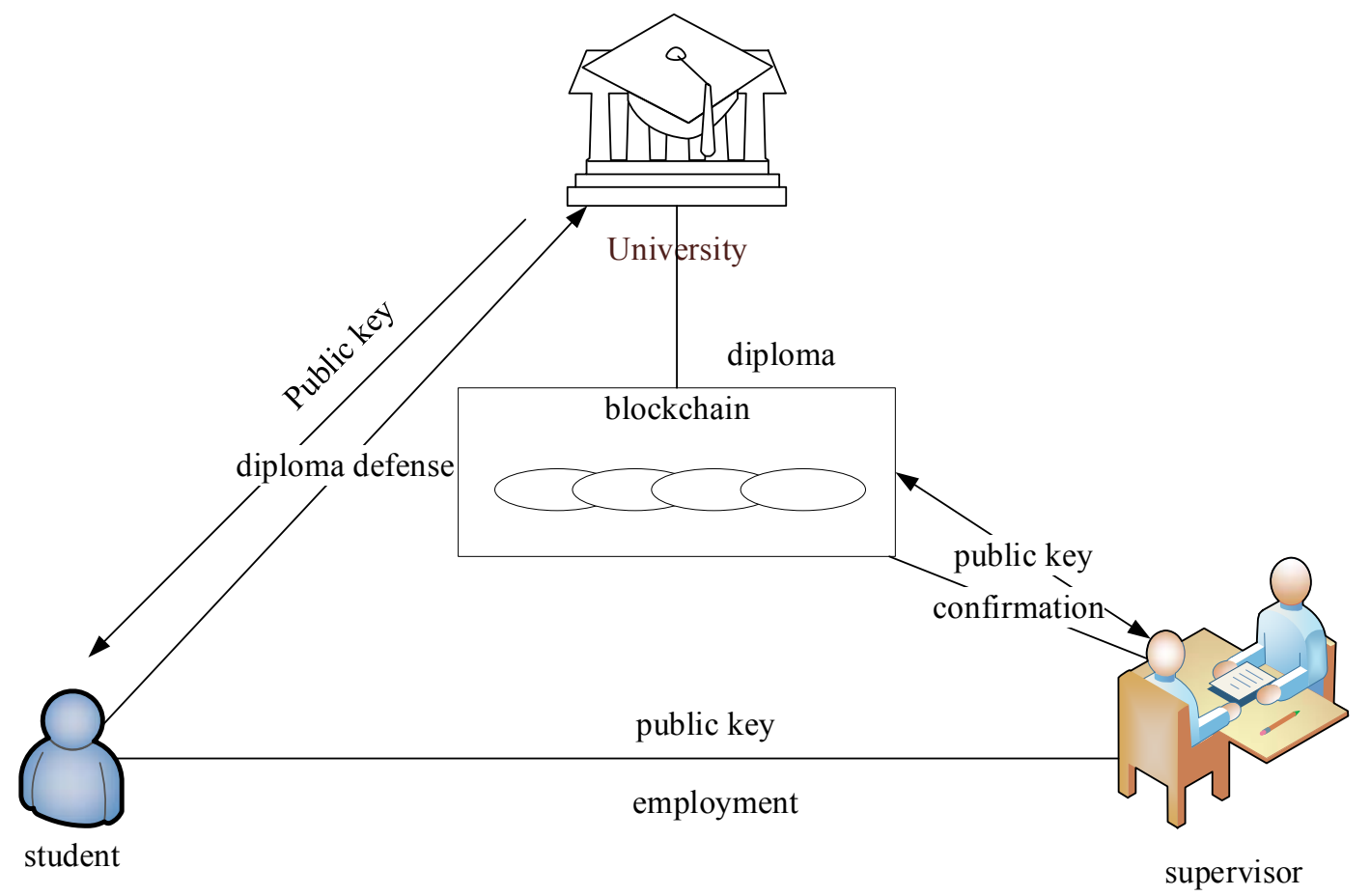

Fig. 4. Educational assets tokenization model 
In this case, higher education institutions that issue digital diplomas (educational assets) will use a single decentralized register to store them.

Genuine diplomas, signed with a private key, will be provided directly to employers. Thus, the verification of the diploma requires only a comparison with the hashes, stored in the chain of blocks. This will solve the problem of document fraud as well as the preservation of confidential documents.

Even if the institution that issued the diploma is closed, the diplomas remain in the distributed database of the blockchain. In addition, one does not need to spend additional resources to verify the authenticity of the document through third parties, the employer can directly verify the diploma in a chain of blocks.

To understand, in detail, the sequence of actions in the blockchain, it is necessary to consider its mechanism of operation.

First of all, a digital token is created, which contains basic information, such as the name of the university and that of the recipient of the diploma, the date of issue, certificate, etc.

Then, the university signs the contents of the diploma using a private key, to which only the educational organization has access. The data is confirmed by the network node and transmitted to the network. The record joins the block.

The university creates a hash file of credentials - a short string of letters and numbers that can be used to verify that no one has violated the contents of the diploma. There is only one possible combination of letters and numbers that corresponds to the digital token of the diploma, and any change will result in a different hash.

Then, the university again uses its private key to create a record in the blockchain, which states that the educational organization has issued a certain certificate to a certain person on a certain date.

Finally, the graduate is given a public key. Thus, the user can check to whom the diploma was issued, by whom as well as check the content of the diploma itself.

The advantages over the current state of affairs are that the evidence of the certificates authenticity will be stored completely, securely and in a permanent blockchain register. Thus, even if the issuing institutions have been closed, these certificates are still being checked for records, stored in the blockchain register. In addition, once the institutions issue a diploma, they do not need to spend additional resources to validate the document to third parties, as they will be able to directly verify diplomas in the form of blockchain chain identification.

The only condition, required to enable this scenario to function, is some software that will allow one to issue signed certificates, placed on the blockchain, as well as the verification software to validate these certificates.

\section{Research results and their discussion}

Several companies are currently launching sovereign self-identification solutions that can be applied to the proposed scenarios. Now this will require educational and scientific organizations to carry out significant technical updating, to link these systems to their student information systems.

Currently, the application of blockchain technologies in educational institutions is in the experimental stages. But there are already universities that have launched pilot projects to implement blockchain technology, such as the Massachusetts Institute of Technology and the University of Nicosia in Cyprus.

Enthusiasts, eager to introduce of digital technologies in education, have many times experienced peaks of hope and downturns of disappointment. Now, they are on another wave of optimism. And this optimism is not related to the tomorrow's technologies, but to what has become publicly available today. Cheap microprocessor kits, components for amateur design of various programmable devices, including robots, examples, to which educational policy pays little attention. But the fundamental change is associated with the formation of a digital educational environment of a modern educational institution, where all educational activities are considered to be part of a single educational process, as well as its outcomes - since the expected results of these activities (training, production). The appearance of a personal digital device (laptop, tablet or smartphone) of each participant in the educational process allows you to work in a digital educational environment via the Internet.

The modern development of the digital economy has led to the practical implementation of the digital transformation of all aspects of human activity, including both the industrial and social spheres.

Currently, technology is evolving very rapidly and is constantly increasing the amount of the received, transmitted and stored information. In this regard, the Big Data technology, which allows one to work with large amounts of data, is becoming popular, as a result, the new blockchain technology is gaining popularity.

According to the existing categorization, there are three conditional areas of application of this technology: blockchain 1.0 is a currency; blockchain 2.0 is contracts; blockchain 3.0 - applications, whose scope goes beyond financial transactions and markets. The last category includes the blockchain in education.

The paper describes the existing process of issuing diplomas and, alternatively, a modern approach of using digital tokens, based on blockchain technology, is proposed in the work. The model of blockchain technology work in education and the mechanism of its application are presented.

The theoretical significance of the study is due to the relevance of the set tasks. The findings and proposals, obtained as a result of the study, complement and develop a number of aspects in the application of blockchain technology in various fields and can serve as a theoretical and practical foundation for conceptualization and optimization of certain organizational innovation in management processes, purtaining the activities of any educational institution.

The practical significance of the study lies in the fact that the provisions and conclusions, set out in the paper, can be used by higher educational institutions of Ukraine in determining the directions of e-learning systems development.

\section{Conclusions}

1. Consideration of the mechanisms and features of blockchain technology leads to the conclusion that such technology is decentralized and 
transparent with a high degree of reliability. Decentralization of technology ensures equality of all users of the services in the chain. The transparency of the technology guarantees the participants in the process against abuse and falsification of documents, which is relevant in the education system.

2. The study of the features of smart contracts made it possible to form the advantages of smart contracts in the field of education. This is, first of all, the conclusion of agreements without the participation of third parties, as well as the security and confidentiality of agreements. This ensures that the terms and subject of the agreement are kept secret, and that no one else can amend the agreement. At the same time, storing the contract in encrypted form ensures its confidentiality. There is also a decrease in the cost of operations.

3. Tokenization of educational assets is considered on the example of preparing and defending a thesis with the subsequent registration of a diploma. The processes of passing the thesis in the context of the use of blockchain technology and registration of smart contracts are considered in detail. The advantages of using blockchain technology and smart contracts are illustrated with specific examples.

\section{References}

1. Nakamoto, S., Bitcoin, A. (2008). Bitcoin: A peer-to-peer electronic cash system. Available at: https://bitcoin.org/bitcoin.pdf

2. Tulchinsky, G. (2017). Digital Transformation of Education: Challenges for Higher School. Russian Journal of Philosophical Sciences, 6, 121-136.

3. Antonova, D. A., Ospennikova, E. V., Spirin, E. V. (2018). TSifrovaya transformatsiya sistemy obrazovaniya. Proektirovanie resursov dlya sovremennoy tsifrovoy uchebnoy sredy kak odno iz ee osnovnykh napravleniy. Vestnik Permskogo gosudarstvennogo gumanitarno-pedagogicheskogo universiteta. Seriya: Informatsionnye kompyuternye tekhnologii $\mathrm{v}$ obrazovanii, 14 . Available at: $\mathrm{https}$ ://cyberleninka.ru/article/n/tsifrovaya-transformatsiya-sistemy-obrazovaniya-proektirovanie-resursov-dlya-sovremennoy-tsifrovoyuchebnoy-sredy-kak-odno-iz-ee

4. Kozlova, N. Sh. (2019). Tsifrovye tekhnologii v obrazovanii. Vestnik Maykopskogo gosudarstvennogo tekhnologicheskogo universiteta, 1.Available at: https://cyberleninka.ru/article/n/tsifrovye-tehnologii-v-obrazovanii

5. Svon, M. (2019). Blokcheyn. Skhema novoy ekonomiki. Moscow: Litres, 311.

6. Di Francesco Maesa, D., Mori, P. (2020). Blockchain 3.0 applications survey. Journal of Parallel and Distributed Computing, 138, 99-114. doi: http://doi.org/10.1016/j.jpdc.2019.12.019

7. Molokovich, D. V. (2018). Integrirovannaya karta studenta kak noviy produkt $\mathrm{v}$ tsifrovom bankovskom obsluzhivanii. Sovremennoe sostoyanie i perspektivy razvitiya natsionalnoy finansovo-kreditnoy sistemy. Voronezh, 154-157.

8. Fedorova, E. P., Skobleva, E. I. (2020). Application of Blockchain Technology in Higher Education. European Journal of Contemporary Education, 9 (3), 552-571. doi: http://doi.org/10.13187/ejced.2020.3.552

9. Tsai, W.-T., Feng, L., Zhang, H., You, Y., Wang, L., Zhong, Y. (2017). Intellectual-Property Blockchain-Based Protection Model for Microfilms. 2017 IEEE Symposium on Service-Oriented System Engineering (SOSE), 174-178. doi: http://doi.org/10.1109/sose.2017.35

10. Tuğtekin, E. B., Dursun, Ö. Ö., Uğur, S. Ş. (2020). Virtual Identity in Blockchain. Advances in Educational Technologies and Instructional Design. IGI Global, 171-196. doi: http://doi.org/10.4018/978-1-5225-9478-9.ch009

11. Kamišalić, A., Turkanović, M., Mrdović, S., Heričko, M. (2019). A Preliminary Review of Blockchain-Based Solutions in Higher Education. Learning Technology for Education Challenges. Cham: Springer, 114-124. doi: http://doi.org/10.1007/978-3030-20798-4 11

12. Mohanta, B. K., Panda, S. S., Jena, D. (2018). An Overview of Smart Contract and Use Cases in Blockchain Technology. 2018 9th International Conference on Computing, Communication and Networking Technologies (ICCCNT). doi: http://doi.org/10.1109/ iccent.2018.8494045

13. Bogner, A., Chanson, M., Meeuw, A. (2016). A Decentralised Sharing App running a Smart Contract on the Ethereum Blockchain. Proceedings of the 6th International Conference on the Internet of Things. doi: http://doi.org/10.1145/2991561.2998465

Received date 15.04.2021

Accepted date 20.05.2021

Published date 31.05.2021

Olexander Shmatko, PhD, Associate Professor, Department of Software Engineering and Information Technology Management, National Technical University "Kharkiv Polytechnic Institute", Kyrpychova str., 2 , Kharkiv, Ukraine, 61002

E-mail: asu.spios@gmail.com

Tetyana Borova, Doctor of Pedagogical Sciences, Professor, Department of Pedagogy, Foreign Philology and Translation, Simon Kuznets Kharkiv National University of Economics, Nauky ave., 9-A, Kharkiv, Ukraine, 61166 E-mail: Tetyana.Borova@hneu.net

Serhii Yevseiev, Doctor of Technical Science, Professor, Department of Cyber Security and Information Technology, Simon Kuznets Kharkiv National University of Economics, Nauky ave., 9-A, Kharkiv, Ukraine, 61166 E-mail: serhii.yevseiev@hneu.net

Oleksandr Milov, Doctor of Technical Science, Professor, Department of Cyber Security and Information Technology, Simon Kuznets Kharkiv National University of Economics, Nauky ave., 9-A, Kharkiv, Ukraine, 61166

E-mail: Oleksandr.Milov@hneu.net 